Check for updates

Cite this: J. Mater. Chem. C, 2017, 5, 7585

Received 31st May 2017,

Accepted 1st July 2017

DOI: $10.1039 / \mathrm{ctc0} 02389 \mathrm{~h}$

rsc.li/materials-c

\section{Transparent conducting n-type ZnO:Sc - synthesis, optoelectronic properties and theoretical insight $\dagger$}

\author{
Sebastian C. Dixon, (D) a Sanjayan Sathasivam, ${ }^{a}$ Benjamin A. D. Williamson, ${ }^{b}$ \\ David O. Scanlon, (D) bc Claire J. Carmalt (iD ${ }^{a}$ and Ivan P. Parkin (D)*a
}

\begin{abstract}
A joint theoretical-experimental study has been carried out for Sc-doped ZnO (SZO), one of the lesserstudied n-type transparent conducting oxide materials. Density functional theory has been used to create a computational model of SZO, in order to provide a theoretical basis for experimentallyobserved phenomena where growth conditions, dopability and electronic properties are concerned. Meanwhile a range of thin films of SZO have been synthesised via chemical vapour deposition in an attempt to (i) observe experimentally the theoretically predicted properties, thereby providing mutual validation of the studies; (ii) seek the optimum dopant quantity for minimal electrical resistivity, and; (iii) demonstrate that transparent and electrically conductive SZO can be synthesised by chemical vapour deposition means. The films exhibit resistivities as low as $\rho=1.2 \times 10^{-3} \Omega \mathrm{cm}$, with carrier density $n=7.2 \times 10^{20} \mathrm{~cm}^{-3}$ and charge carrier mobility $\mu=7.5 \mathrm{~cm}^{2} \mathrm{~V}^{-1} \mathrm{~s}^{-1}$. Low resistivity of the films was retained after 12 months in storage under ambient conditions, indicating strong atmospheric stability. The films exhibit a high degree of transparency with $88 \%$ transmission in the visible range $(400-750 \mathrm{~nm})$. A correction to the Tauc method was applied to estimate band gaps of $E_{\mathrm{g}}^{\mathrm{opt}}=3.45 \pm 0.03 \mathrm{eV}$ in the most conductive SZO sample and $E_{\mathrm{g}}^{\mathrm{opt}}=3.34 \pm 0.03 \mathrm{eV}$ in nominally undoped $\mathrm{ZnO}$.
\end{abstract}

\section{Introduction}

Transparent conducting oxide (TCO) thin films are widely adopted in optoelectronic devices as transparent electrodes. The unique properties of these indispensable materials are unusual by traditional principles; the wide band gap required for optical transparency $\left(E_{\mathrm{g}}>3.1 \mathrm{eV}\right)$ which separates the valence band (VB) from the conduction band (CB) leads to highly resistive semiconductor behaviour in pure stoichiometric $\mathrm{ZnO}$, due to the low probability of electron excitation across this threshold. However, doping of the material offers a solution to this dilemma; extrinsic doping by artificial introduction of substitutional impurities such as $\left.\mathrm{Al}^{(\mathrm{III}}\right)^{1}$ or $\mathrm{Ga}(\mathrm{III})^{2}$ on $\mathrm{Zn}$ (II) crystallographic sites results in an effective local excess of electrons at the defect sites. This produces an electron donor level close to the $\mathrm{CB}$ minimum (CBM), which facilitates donation of electrons into the $\mathrm{CB}$ to confer electrical conductivity to the material whilst the wide optical band gap is retained. In this way, it is possible to

\footnotetext{
${ }^{a}$ Materials Chemistry Centre, Department of Chemistry, University College London, 20 Gordon Street, London WC1H OAJ, UK. E-mail: i.p.parkin@ucl.ac.uk; Fax: +44 (o)20 769 7463; Tel: +44 (o)20 76794669

${ }^{b}$ Kathleen Lonsdale Materials Chemistry, Department of Chemistry,

University College London, 20 Gordon Street, London WC1H OAJ, UK

${ }^{c}$ Diamond Light Source Ltd, Diamond House, Harwell Science and Innovation

Campus, Didcot, Oxfordshire OX11 ODE, UK

$\dagger$ Electronic supplementary information (ESI) available. See DOI: 10.1039/c7tc02389h
}

synthesise transparent and conducting inorganic materials such as $\mathrm{ZnO}:\left(\mathrm{Al},{ }^{1} \mathrm{Ga},{ }^{2} \mathrm{~F},{ }^{3} \mathrm{Sc}^{4}\right)$ and $\mathrm{SnO}_{2}: \mathrm{F}^{5}$ by extrinsic doping of the semiconductor. ${ }^{6}$ The most widely used TCO material is $\operatorname{~n}_{2} \mathrm{O}_{3}: \mathrm{Sn}$ (ITO), which is a high-performance material demonstrating high optical transmission in the visible $(>90 \%$ at $550 \mathrm{~nm})$ and low electrical resistivities $\left(\rho=10^{-4}-10^{-5} \Omega \mathrm{cm}\right)^{7}$ However, due to its low natural abundance and localised geological distribution, the commercial supply of indium is expensive and in a perpetual state of risk, which is problematic for various reasons. ${ }^{8}$ As such, it has naturally become desirable to seek an alternative to ITO as a commercial TCO, which is evident from the amount of research dedicated to this end in recent years.

Computational modelling of potential TCO systems has become an important and indispensable method for their high-throughput screening, ${ }^{9}$ often working side-by-side with experimental synthesis work to quickly seek ideal doping scenarios and provide a more complete picture of the origin of observable physical properties. ${ }^{10}$ While Al-doped and Ga-doped $\mathrm{ZnO}$ have received much attention as extrinsically n-type doped $\mathrm{ZnO}$ systems in recent years, reports on other trivalent dopants are reported considerably less often. In particular, Sc-doped ZnO (SZO) has shown promise as an alternative TCO material with low resistivity and high visible transmittance, ${ }^{4,11}$ however with relatively few deposition studies having been carried out and still fewer theoretical studies developing an understanding of this material. Development of a computational model to describe the behaviour of Sc doping 
in $\mathrm{ZnO}$ is crucial to achieving this. The present work represents the first such instance, in which density functional theory has been applied to construct a theoretical model of the doping behaviour of Sc in ZnO. The theoretical model is developed alongside a strongly correlated experimental synthesis of ZnO:Sc via aerosol-assisted chemical vapour deposition.

Chemical vapour deposition (CVD) is a commonly adopted means by which to achieve deposition of TCO thin films, which is performed by delivery of a well-mixed vapour containing precursors of the host and dopant oxides to the heated substrate, whereupon thermal decomposition occurs to yield the desired material from the vapour. Traditional CVD, usually referred to as thermal, metal-organic or atmospheric-pressure CVD (APCVD), generates these vapours from thermal heating of volatile precursors such as diethyl zinc ${ }^{3}$ with an oxygen source such as ethanol and a dopant source such as trifluoroethanol (in the case of F-doped $\mathrm{ZnO}$ deposition). ${ }^{3}$ However, in order for this technique to be effective there is a fundamental requirement that the (often liquid) precursor has an appreciable vapour pressure, which, aside from restricting the scope of precursor selection for a given target material, also naturally leads to precursors with inherent hazards such as flammability, pyrophoricity, explosivity, corrosivity and respiratory and environmental toxicity. This leads to obvious complications regarding their transport, storage, usage and disposal. ${ }^{12}$ Such considerations have given rise to a more versatile method of CVD in recent years known as aerosol-assisted CVD (AACVD), in which a solution of the precursor is aerosolised in order to generate the vapour. ${ }^{13}$ This alternative enables use of a much more diverse range of potential precursors, whose only requirements are: (a) that the precursor decomposes below the set deposition temperature to yield the desired material, and (b) that the precursor is soluble in a suitable solvent (e.g. methanol, chloroform, toluene). ${ }^{12}$ As such, a popular choice for AACVD precursor selection is an inorganic or organic salt of the desired element such as indium chloride or zinc acetate (in the case of $\mathrm{ZnO}$ :In films), ${ }^{14}$ which is often cheap, readily available and usually comes with fewer significant associated physical hazards compared to its volatile liquid counterpart. In addition to this, AACVD permits 'one-pot' depositions, where precursors with similar solubility can be dissolved in a common solvent and deposited together from a single precursor flask. Such a method is ideal for doping studies, where it is desirable to produce a well-mixed vapour with a highly controllable chemical composition. As such, it is the method of choice in the present study for Sc-doping of $\mathrm{ZnO}$.

\section{Methodology}

\subsection{Materials}

Zinc(II) acetate ([Zn(OAc) $\left.\left.)_{2}\right]\right)$ and scandium(III) acetate $\left(\left[\mathrm{Sc}(\mathrm{OAc})_{3}\right]\right)$ were obtained from Sigma-Aldrich. Nitrogen carrier gas $\left(\mathrm{N}_{2}\right.$, 99.99\%) was obtained from BOC. Methanol (99.5\%) was obtained from Merck Millipore. All of the above chemicals were used as supplied. Float glass with a $25 \mathrm{~nm} \mathrm{SiO}_{2}$ barrier layer was provided by NSG Pilkington Ltd and cut manually into substrates $(50 \times 145 \times 4 \mathrm{~mm})$.

\subsection{Experimental procedure}

In a typical deposition, zinc(II) acetate $(0.69 \mathrm{~g}, 3.0 \mathrm{mmol})$ was dissolved in methanol (35 mL) with stirring. Scandium(III) acetate was dissolved in a minimum volume of deionised water (ca. $5 \mathrm{~mL}$ ) with swirling. The methanol solution was added to the aqueous solution followed by stirring for ca. $10 \mathrm{~min}$. Varying molar ratios of the Sc to $\mathrm{Zn}$ precursor were used to deposit a range of films with varying Sc content. In the $3 \mathrm{~mol} \%$ Sc:Zn film, the amount of scandium(III) acetate to use $(0.021 \mathrm{~g}$, $0.090 \mathrm{mmol}$ ) was calculated from the amount of zinc(II) acetate in the solution. Precursor solutions containing 0.0, 1.0, 2.0, 3.0 and $4.0 \mathrm{~mol} \% \mathrm{Sc}: \mathrm{Zn}$ content were prepared in this manner. Higher proportions of aqueous Sc precursor presented miscibility issues with the alcoholic $\mathrm{Zn}$ precursor solution, therefore placing an upper limit to the quantity of dopant deliverable by this method.

The precursor solution was transferred to a glass AACVD bubbler for deposition. Silica barrier glass substrates were cleaned prior to deposition with detergent, isopropyl alcohol and acetone, whereupon they were positioned atop a graphite block within the cold-walled horizontal-bed reactor chamber. The graphite block contained a Whatman cartridge heater regulated by a Pt-Rh thermocouple. A sheet of stainless steel $(45 \times 150 \mathrm{~mm})$ was supported at a height of $8 \mathrm{~mm}$ above the substrate to assist with laminar flow of the precursor aerosol over the substrate. This arrangement was enclosed by a quartz tube. Polytetrafluoroethylene tubing (PTFE, $8 \mathrm{~mm}$ internal diameter) served to deliver the aerosol from the precursor vessel to a brass baffle manifold which homogenised the flow of aerosol into the attached reaction chamber. Nitrogen carrier gas was passed throughout, arriving first at the precursor vessel then travelling along the tubing, through the baffle and into the reactor chamber between the glass and copper plates, then at last out of the far exhaust. The nitrogen was allowed to flow in this way for $c a .10$ min prior to aerosolisation of the precursor in order to allow for equilibration of the deposition environment. The reaction chamber was heated at a rate of $15{ }^{\circ} \mathrm{C} \mathrm{min}{ }^{-1}$ to its target temperature of $600{ }^{\circ} \mathrm{C}$, at which point aerosolisation of the precursor was commenced using a Johnson Matthey Liquifog ${ }^{\circledR}$ piezoelectric ultrasonic humidifier approximately half-filled with deionised water. The carrier gas transported the aerosol at a fixed rate of $2.0 \mathrm{~L} \mathrm{~min}^{-1}$. The deposition process was allowed to proceed in this manner until all of the precursor solution had been aerosolised, at which point the humidifier and heating elements were shut off and the substrate allowed to cool under continual flow of nitrogen. Once the reactor had reached below $100{ }^{\circ} \mathrm{C}$, the samples were removed from the reactor and handled in air.

\subsection{Characterisation details}

$\mathrm{X}$-ray diffractometry was conducted at glancing angle $\left(\theta=0.8^{\circ}\right)$ in air using a Bruker D8 Discover diffractometer in the range $2 \theta=10-66^{\circ}$ with monochromatic $\mathrm{Cu} \mathrm{K}_{\alpha 1}$ and $\mathrm{K}_{\alpha 2}$ radiation (1.54056 and $1.54439 \AA$ A respectively) under voltage $40 \mathrm{kV}$ and current $40 \mathrm{~mA}$. X-ray photoelectron spectroscopy was conducted 
using a Thermo Scientific K-alpha spectrometer with monochromated $\mathrm{Al} \mathrm{K}_{\alpha}$ radiation (1486.68 eV), a dual-beam charge compensation system and a constant pass energy of $50 \mathrm{eV}$ with spot size $400 \mu \mathrm{m}$. Survey scans were collected for the binding energy range 0-1200 eV. Data was calibrated against C 1s (284.5 eV) and fitted using CASA XPS software. UV-visible spectra were taken using a Perkin Elmer Lambda 950 UV/Vis/NIR Spectrophotometer in transmission mode. A Labsphere reflectance standard was used as a reference. Scanning electron microscopy was conducted on a JEOL 6700F SEM using an acceleration voltage of $20 \mathrm{kV}$, with an attached Oxford Instruments INCA Energy EDXA system operated at $15 \mathrm{kV}$. Hall effect measurements were taken using the Van der Pauw four-point probe configuration at room temperature to measure the resistivity of the films, their free charge carrier concentrations and mobilities. Measurements were performed using an Ecopia HMS-3000 instrument with a $0.58 \mathrm{~T}$ permanent magnet and a current of $1 \mathrm{~mA}$, using square-cut coupons ( $c a$. $1 \times 1 \mathrm{~cm})$ of the deposited films. Silver paint obtained from Agar Scientific was used at each of the four corners on the films to enhance Ohmic contact between the Au electrodes and the film. Thermogravimetric analysis (TGA) and differential scanning calorimetry (DSC) were performed under helium using a Netzsch STA 449 C Jupiter Thermo-microbalance in an open aluminium oxide crucible.

\subsection{Computational methodology}

All density functional theory (DFT) calculations were carried out using the Vienna ab initio simulation package (VASP). ${ }^{15-18}$ Within this code a plane-wave basis set is used to describe the valence electronic states and the projector-augmented wave $(\mathrm{PAW})^{19}$ method which maps the core electrons (treated with pseudopotentials) onto the valence electrons (treated explicitly) for computational efficiency, giving results akin to an all electron method. ZnO crystallises in the wurtzite crystal structure $\left(\mathrm{P6}_{3} \mathrm{mc}\right)$. In order to counteract the self-interaction error (SIE) and thus band gap errors typical to standard DFT functionals, the hybrid functional Heyd-Scuzeria-Ernzerhoff (HSE) ${ }^{20}$ was employed for all calculations.

Hybrid functionals improve on standard functionals in improving geometric and electronic structure compared to experiment. ${ }^{21-41}$ Standard DFT functionals such as generalised gradient approximation (GGA) or local density approximation (LDA) fall short in their description of the self-interaction error which typically leads to underestimated band gaps, this is known to affect the defect thermodynamics. ${ }^{42-44}$ The HSE06 approach adds $25 \%$ of HF exchange $(\alpha=0.25)$ however HSE with $37.5 \%$ exchange has been reported to yield geometric and electronic structures in good agreement with experiment. ${ }^{30,45}$

The lattice parameters $(a, b, c)$, enthalpy of formation $\left(\Delta H_{\mathrm{f}}\right)$ and band gap ( $\left.E_{\mathrm{g}}^{\mathrm{dir}}\right)$ for bulk $\mathrm{ZnO}$ compared to experiment and other DFT studies are shown in Table 1. It is clear that using HSE with $37.5 \%$ HF exchange gives structural, electronic and thermodynamic results closest to experimental low temperature studies. ${ }^{45-48}$ The direct fundamental band gap $\left(E_{\mathrm{g}}^{\mathrm{dir}}\right)$ calculated in this work matches to within $1.5 \%$ of the experimentally defined band gap for $\mathrm{ZnO}$, similar to the study carried out by
Table 1 Lattice parameters $(a, b, c)$, enthalpy of formation $\left(\Delta H_{f}\right)$ and band gap $\left(E_{\mathrm{g}}^{\text {dir }}\right)$ for bulk $\mathrm{ZnO}$, as calculated in the present work and compared with other DFT and experimental work

\begin{tabular}{lllll}
\hline & $a, b(\AA)$ & $c(\AA)$ & $\Delta H_{\mathrm{f}}(\mathrm{eV})$ & $E_{\mathrm{g}}^{\text {dir }}(\mathrm{eV})$ \\
\hline This work, HSE $(\alpha=0.375)$ & 3.25 & 5.21 & -3.25 & 3.39 \\
${\text { LDA }+U^{49}}^{39}(\alpha=0.25)$ & 3.25 & 5.12 & -3.50 & 1.51 \\
HSE06 $^{39}(\alpha .26$ & 5.24 & -3.01 & 2.46 \\
PBE0 $^{30}$ & 3.26 & 5.22 & -3.03 & 3.18 \\
HSE $(\alpha=0.375)^{30}$ & 3.24 & 5.19 & -3.13 & 3.43 \\
Experiment $^{45-48}$ & 3.25 & 5.21 & -3.62 & 3.44
\end{tabular}

Oba et al. ${ }^{30}$ which also used $37.5 \%$ HF exchange. The enthalpy of formation $\left(\Delta H_{\mathrm{f}}\right)$ also matches the experimental value to within $10 \%$ despite the calculations being carried out at the athermal limit $(T=0 \mathrm{~K})$.

In order to simulate the effect of intrinsic defects and extrinsic dopants in $\mathrm{ZnO}$, a $3 \times 3 \times 2$ supercell containing 72 atoms was created. Each calculation was spin polarised and the ions were relaxed using an energy cutoff of $450 \mathrm{eV}$ and a $2 \times 2 \times 2 \Gamma$-centred $k$-point mesh. When the forces on all the atoms were less than $0.01 \mathrm{eV}$, the system was deemed to be converged.

2.4.1. Defect formalism. The formation energies of each defect in charge state $q$ was defined as per eqn (1). Where $E^{D, q}$ is the energy of the defective supercell in charge state $q$ and $E^{\mathrm{H}}$ is the energy of the host supercell. $E_{i}$ and $\mu_{i}$ refer to the elemental reference energies $\left(\mathrm{Zn}_{(\mathrm{s})}, \mathrm{O}_{2(\mathrm{~g})}\right.$ and $\left.\mathrm{Sc}_{(\mathrm{s})}\right)$ and the associated chemical potential respectively. $n$ refers to the number of electrons either added to or taken away from an external reservoir. ${ }^{50}$ The Fermi energy ranges from the valence band maximum (VBM) to the conduction band minimum (CBM) and $\varepsilon_{\mathrm{VBM}}^{\mathrm{H}}$ corresponds to the eigenvalue of the VBM in the host supercell. Finally, $E_{\text {corr }}[q]$ allows for corrections due to 'finite size effects', this is usually split into three corrections; (i) the potential alignment which aligns the VBM of the host supercell and the VBM of the defective supercell, (ii) an image charge correction which accounts for the interaction with the charged defect and its periodic images due to the long ranged nature of the Coulomb interaction. ${ }^{51,52}$ The correction scheme used for this takes into account the dielectric tensor in a method laid out by Murphy et al. ${ }^{53}$ Lastly (iii) a band filling correction is applied to account for the high defect concentrations present in supercells in a formalism defined by Lany and Zunger. ${ }^{42,54}$

$$
\begin{aligned}
\Delta H_{\mathrm{f}}(D, q)= & \left(E^{D, q}-E^{\mathrm{H}}\right)+\sum_{i} n_{i}\left(E_{i}+\mu_{i}\right) \\
& +q\left(E_{\mathrm{Fermi}}+\varepsilon_{\mathrm{VBM}}^{\mathrm{H}}\right)+E_{\text {corr }}[q]
\end{aligned}
$$

2.4.2. Thermodynamic limits. The equilibrium growth conditions are reflected in the chemical potentials, $\mu_{i}$ which, when varied, can simulate the experimental partial pressures defining the conditions of $n$ and p-type defect formation. This is done within the constraint of the calculated enthalpy of the host, as per eqn (2).

$$
\mu_{\mathrm{Zn}}+\mu_{\mathrm{O}}=\Delta H_{\mathrm{f}}^{\mathrm{ZnO}}=-3.25 \mathrm{eV}
$$

The Zn-rich/O-poor conditions (which typically favour the formation of $n$-type defects) are determined by the formation of 
metallic $\mathrm{Zn}$ i.e. $\Delta \mu_{\mathrm{Zn}}=0 ; \Delta \mu_{\mathrm{O}}=-3.25 \mathrm{eV}$. Likewise for $\mathrm{Zn}$-poor/ O-rich conditions (where p-type defect formation is favoured) the limit is determined by the formation of $\mathrm{O}_{2}$ gas, $\Delta \mu_{\mathrm{O}}=0$; $\Delta \mu_{\mathrm{Zn}}=-3.25 \mathrm{eV}$. Alongside this, the solubilities of the dopantrelated species are limited by the formation of the secondary phase $\mathrm{Sc}_{2} \mathrm{O}_{3}$, as shown in eqn (3), while the limited solubility of $\mathrm{Sc}$ in $\mathrm{ZnO}$ has also been noted in previous experimental study. ${ }^{55}$ Therefore, under Zn-poor/O-rich conditions and O-poor/Zn-rich conditions the Sc chemical potentials can be calculated to be $\Delta \mu_{\mathrm{Sc}}=-9.75 \mathrm{eV}$ and $\Delta \mu_{\mathrm{Sc}}=-4.87 \mathrm{eV}$ respectively. It should be noted that the uppermost dopant quantity used in this study represents the miscibility limit of the aqueous Sc precursor with the methanolic $\mathrm{Zn}$ precursor in the one-pot precursor vial, rather than the chemical solubility limit described here.

$$
2 \mu_{\mathrm{Sc}}+3 \mu_{\mathrm{O}}=\Delta H_{\mathrm{f}}^{\mathrm{Sc}_{2} \mathrm{O}_{3}}=-19.49 \mathrm{eV}
$$

The thermodynamic transition (ionisation) levels of a given defect illustrate the Fermi level position at which that defect changes from charge state $q$ to $q^{\prime}$, which is calculated as per eqn (4). These transition levels are shown in Fig. 3. These ionisation levels are experimentally important as they can be observed using techniques such as deep level transient spectroscopy (DLTS).

$$
\varepsilon_{\mathrm{D}} \frac{q}{q^{\prime}}=\frac{\Delta H_{\mathrm{f}}(D, q)-\Delta H_{\mathrm{f}}\left(D, q^{\prime}\right)}{q^{\prime}-q}
$$

\section{Results and discussion}

\subsection{Computational study}

The density of states (DOS) and band structure for bulk ZnO are shown in Fig. 1 and 2 respectively. In the DOS, the VBM is predominantly made up of $\mathrm{O} 2 \mathrm{p}$ states with some $\mathrm{Zn} \mathrm{p}$ and $\mathrm{d}$ mixing, typical of wide band gap metal oxide semiconductors such as $\mathrm{In}_{2} \mathrm{O}_{3}, \mathrm{SnO}_{2}, \mathrm{TiO}_{2}$ and $\mathrm{BaSnO}_{3}{ }^{41,56,57}$ The CBM is made up of primarily $\mathrm{Zn}$ s states with $\mathrm{O} s$ and $\mathrm{p}$ states. The band structure shown of $\mathrm{ZnO}$ displays a direct band gap at $\Gamma(3.39 \mathrm{eV})$ with the characteristically highly disperse CBM. The effective electron mass is $c a .0 .27 m_{\mathrm{e}}$ in both the $\Gamma-K$ and $\Gamma-M$ directions, which compares well with experimental values of $0.28 \mathrm{me}^{58}$ There is also a large CBM to CBM +1 intraband spacing ( $c a$. $4 \mathrm{eV}$ ) present allowing for the accommodation of extra charge carriers whilst retaining the high optical transparency.

Fig. 3 shows defect formation energies within Sc-doped $\mathrm{ZnO}$ as a function of Fermi energy position under (a) Zn-rich/O-poor and (b) Zn-poor/O-rich conditions. Under typical n-type conditions (Zn-rich/O-poor), the formation energies of positively charged defects should be lower in energy than those of negatively charged defects. Under these conditions the dominant intrinsic donor defect is $V_{\mathrm{O}}$ at Fermi energies just below the CBM which acts as a deep donor (i.e. the 2+/0 transition level occurs $c a$. $1.15 \mathrm{eV}$ below the CBM) which is consistent with experimental and theoretical studies alike, ${ }^{30,32,49,59-64}$ meaning that $V_{\mathrm{O}}$ does not contribute to the conductivity of $\mathrm{ZnO}$. This type of "negative $U$ " type behaviour of $V_{\mathrm{O}}$ in wide band gap TCOs is well known. ${ }^{21}$ The high

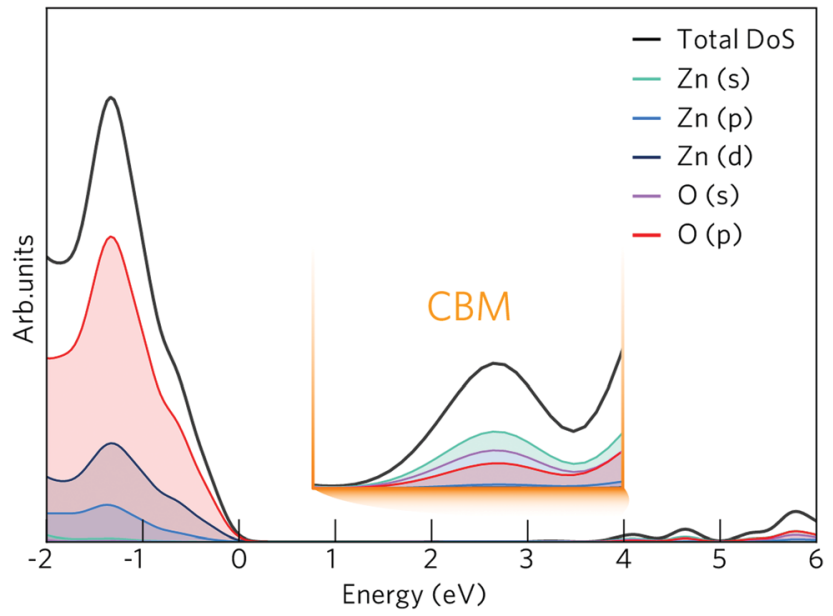

Fig. 1 The calculated density of states (DOS) for $\mathrm{ZnO}$ shown with an expanded view of the conduction band minimum (CBM) inset. The VBM is centred at $0 \mathrm{eV}$.

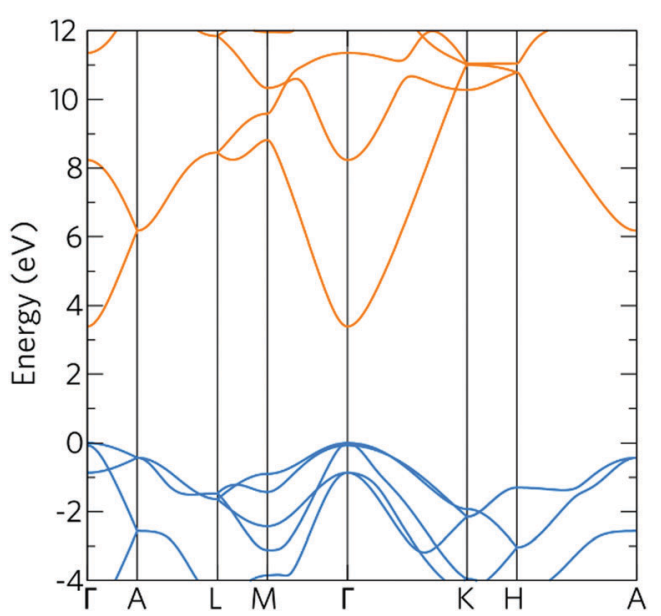

Fig. 2 The calculated band structure for bulk $\mathrm{ZnO}$, calculated using the HSE hybrid functional with $37.5 \%$ HF exchange. The valence bands are indicated in blue and the conduction bands in orange. The valence band maximum is set to $0 \mathrm{eV}$.

conductivity of "undoped" $\mathrm{ZnO}$ has since been attributed to the presence of unintentional hydrogen doping from synthesis forming a shallow donor state below the CBM at formation energies as low as $V_{\mathrm{O}}$ and has been confirmed experimentally using muon spectroscopy. ${ }^{30,65,66}$ However, the $\mathrm{Sc}_{\mathrm{Zn}}$ defect appears to possess a somewhat significant formation energy (ca. $1.55 \mathrm{eV}$ at the $\mathrm{CBM}$ ) while acting as a resonant donor, injecting its excess electron directly into the conduction band. Importantly, this defect does not seem to be compensated for by any intrinsic acceptor defects until well above the CBM under these growth conditions. From this it is expected that incorporation of a high concentration of Sc would be quite difficult under equilibrium conditions, indicating that nonequilibrium growth techniques such as molecular beam epitaxy (MBE) or sputtering could be sensible methods to achieve a higher level of doping. The $V_{\mathrm{Zn}}$ intrinsic defect states are very 

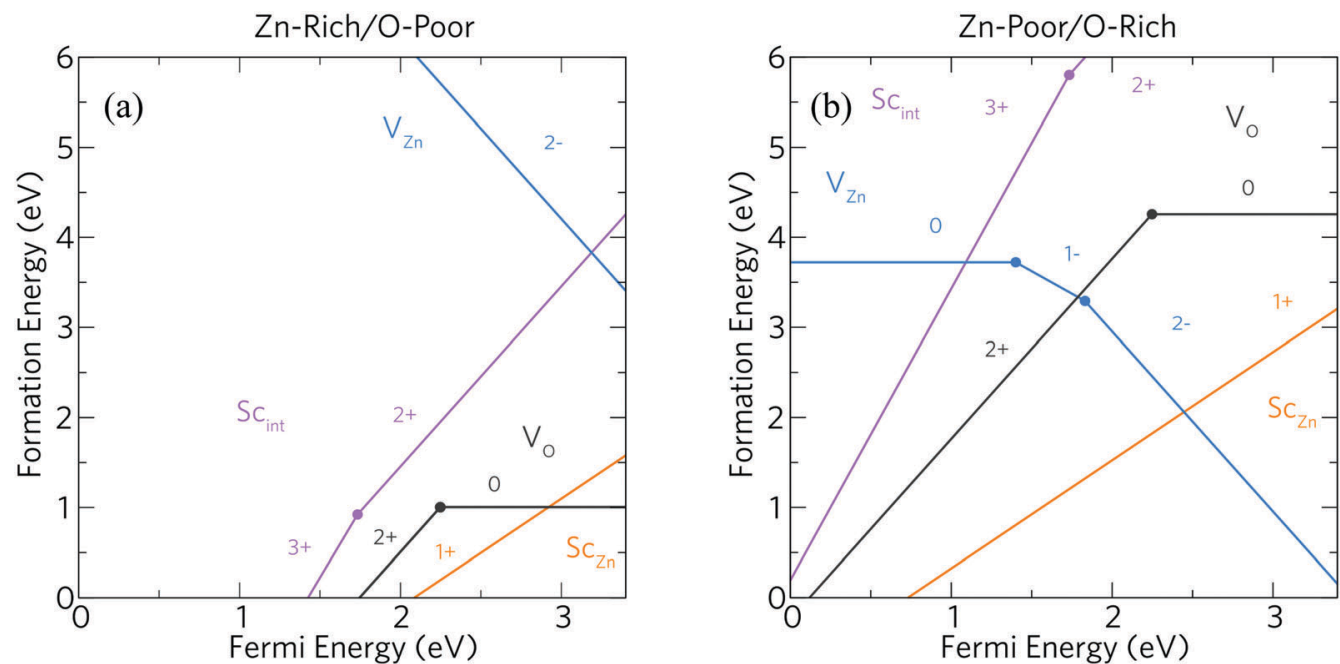

Fig. 3 Calculated formation energies as a function of Fermi energy for intrinsic defects $\left(V_{\mathrm{O}}\right.$, black and $V_{Z n}$, blue) alongside Sc dopant states, substitutional $\mathrm{SC}_{\mathrm{Zn}}$ (orange) and interstitial $\mathrm{Sc}_{\text {int }}$ (pink) under (a) Zn-rich/O-poor and (b) Zn-poor/O-rich conditions. The solid dots indicate the transition levels $\varepsilon\left(q / q^{\prime}\right)$.

high in energy and as such concentrations of this defect will be negligible under these conditions (the formation energy of the neutral charge state is $c a .6 .97 \mathrm{eV}$ which compares well with the hybrid DFT work carried out by Oba $e t$ al. ${ }^{30}$ and with LDA work by Van de Walle and coworkers $\left.{ }^{49}\right)$. $\mathrm{Sc}_{\text {int }}$ also acts as a shallow donor, however under $\mathrm{Zn}$-rich/O-poor conditions we can see it has a particularly high formation energy. Therefore, Sc will be incorporated preferentially on the $\mathrm{Zn}$ site, such that occurrence of $\mathrm{Sc}_{\text {int }}$ is unlikely in the AACVD samples prepared here.

Fig. 3(b) displays the Zn-poor/O-rich conditions favouring the growth of acceptor defects and has the effect of pushing the donor defects $\left(V_{\mathrm{O}}, \mathrm{Sc}_{\mathrm{Zn}}\right.$ and $\left.\mathrm{Sc}_{\mathrm{int}}\right)$ higher in energy. Here, the formation energy of the neutral charge state of $V_{\mathrm{Zn}}$ is reduced and is shown to be a deep acceptor with the 0/1-transition level appearing at $c a .1 .5 \mathrm{eV}$ above the VBM, at a relatively high formation energy of $c a$. $3.7 \mathrm{eV}$. The 1-/2-transition state level occurs $c a .1 .8 \mathrm{eV}$ above the VBM with a formation energy of $c a$. $3.3 \mathrm{eV}$. These results are in contrast to the transition levels calculated in other theoretical works which shows the 0/1and 1-/2-levels to occur $c a .0 .8 \mathrm{eV}$ and $c a .2 .5 \mathrm{eV}$ above the VBM respectively with formation energies of $c a .4 \mathrm{eV}$ and $c a$. $2 \mathrm{eV}^{30,40,49,60}$ Our calculations propose that the 0/1-transition level is $0.7 \mathrm{eV}$ deeper than previously thought whereas the 1-/2level is in fact shallower by $c a$. $0.7 \mathrm{eV}$. One plausible reason for the deeper acceptor levels in our calculations is due to the correct description of hole localisation on the neighbouring $\mathrm{O}$ atoms as shown in Fig. 4; (a) shows the localisation of two holes for the neutral charge state of $V_{\mathrm{Zn}}$, and (b) shows the removal of one hole to form the 1-charge state. This localisation is important for correct lattice relaxation and therefore affects the total energy of the system. ${ }^{67}$ This reduces the neutral vacancy and 1-charge state pushing the transition state energies deeper into the band gap. The only work found where this hole localisation is addressed is in work by Clark et al., where calculations using a "screened exchange" functional show a small localisation on the 1-charge state, however this localisation is small and which will not change the thermodynamic picture much from previous works. ${ }^{40}$

Under $\mathrm{Zn}$-poor/O-rich conditions, $\mathrm{Sc}_{\mathrm{Zn}}$ is the dominant donor defect close to the CBM but is fully compensated for by $V_{\mathrm{Zn}}$, thereby pinning the Fermi level $c a$. $0.9 \mathrm{eV}$ below the CBM; as such, under these conditions no favourable scandium doping will be achieved. Thus, it is clear that Sc-doped $\mathrm{ZnO}$ samples grown close to the limit of O-rich conditions will be insulating, and some degree of O-poor conditions are necessary to achieve efficient n-type conductivity.

\subsection{Synthesis and characterisation}

Thermogravimetric analysis (TGA) and differential scanning calorimetry (DSC) were carried out under helium on the $\left[\mathrm{Sc}(\mathrm{OAc})_{3}\right]$ precursor in order to observe its response to the temperatures applied in the deposition. The TGA shown in Fig. 5 indicates that the $\left[\mathrm{Sc}(\mathrm{OAc})_{3}\right]$ begins to decompose towards $\mathrm{Sc}_{2} \mathrm{O}_{3}$ at around $300{ }^{\circ} \mathrm{C}$, with the transition largely complete by around $380{ }^{\circ} \mathrm{C}$. DSC indicates that this decomposition is sharply endothermic, and seems to feature an overlapping between a peak at $340{ }^{\circ} \mathrm{C}$ and a stronger peak at $360^{\circ} \mathrm{C}$, while a weaker endothermic feature is also apparent at $500-600{ }^{\circ} \mathrm{C}$. While a previous study of the thermal decomposition of $\left[\mathrm{Sc}(\mathrm{OAc})_{3}\right]$ is difficult to find, the thermal decomposition of rare earth metal acetates $\left(\left[\operatorname{Ln}(\mathrm{OAc})_{3}\right]\right)$ is well-documented. ${ }^{68}$ Assuming a similar decomposition pathway for $\left[\mathrm{Sc}(\mathrm{OAc})_{3}\right]$, these endothermic stages can be ascribed to the following processes:

$$
\begin{gathered}
2\left[\mathrm{Sc}(\mathrm{OAc})_{3}\right] \rightarrow \mathrm{Sc}_{2}\left(\mathrm{CO}_{3}\right)_{3}+3 \mathrm{CH}_{3} \mathrm{COCH}_{3} \text { at } 340{ }^{\circ} \mathrm{C} ; \\
\mathrm{Sc}_{2}\left(\mathrm{CO}_{3}\right)_{3} \rightarrow \mathrm{Sc}_{2} \mathrm{O}_{3} \cdot \mathrm{CO}_{2}+2 \mathrm{CO}_{2} \text { at } 360{ }^{\circ} \mathrm{C} \text {, then; } \\
\mathrm{Sc}_{2} \mathrm{O}_{3} \cdot \mathrm{CO}_{2} \rightarrow \mathrm{Sc}_{2} \mathrm{O}_{3}+\mathrm{CO}_{2} \text { at } 500-600{ }^{\circ} \mathrm{C} .
\end{gathered}
$$

A similar result has also previously been observed in the thermal decomposition of scandium formate $\left(\left[\mathrm{Sc}\left(\mathrm{HCO}_{2}\right)_{3}\right]\right)$, which also followed an endothermic decomposition pathway 

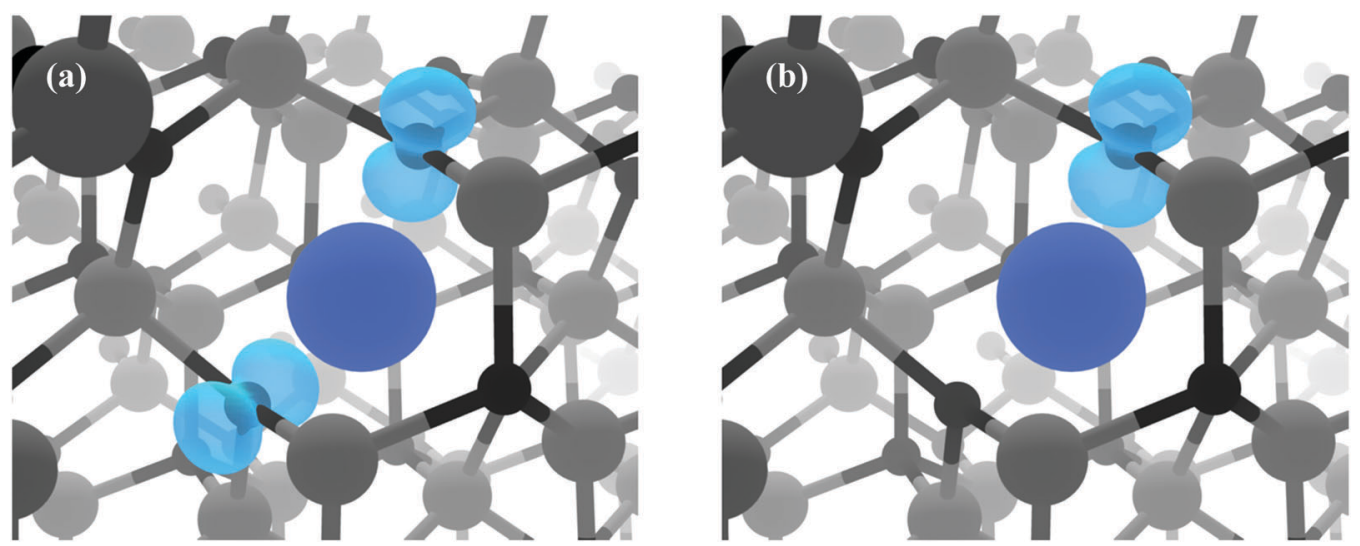

Fig. 4 A close up view of the $V_{Z n}$ for (a) the neutral charge state and (b) the 1-charge state. These diagrams show the localised holes (blue charge isosurface with a density of $0.02 \mathrm{eV} \AA^{-1}$ ) associated with the deep $V_{Z n}$ states. The $Z n$ vacancy is shown by the large blue sphere, whilst $Z n$ and $O$ atoms are depicted as grey and black spheres respectively.

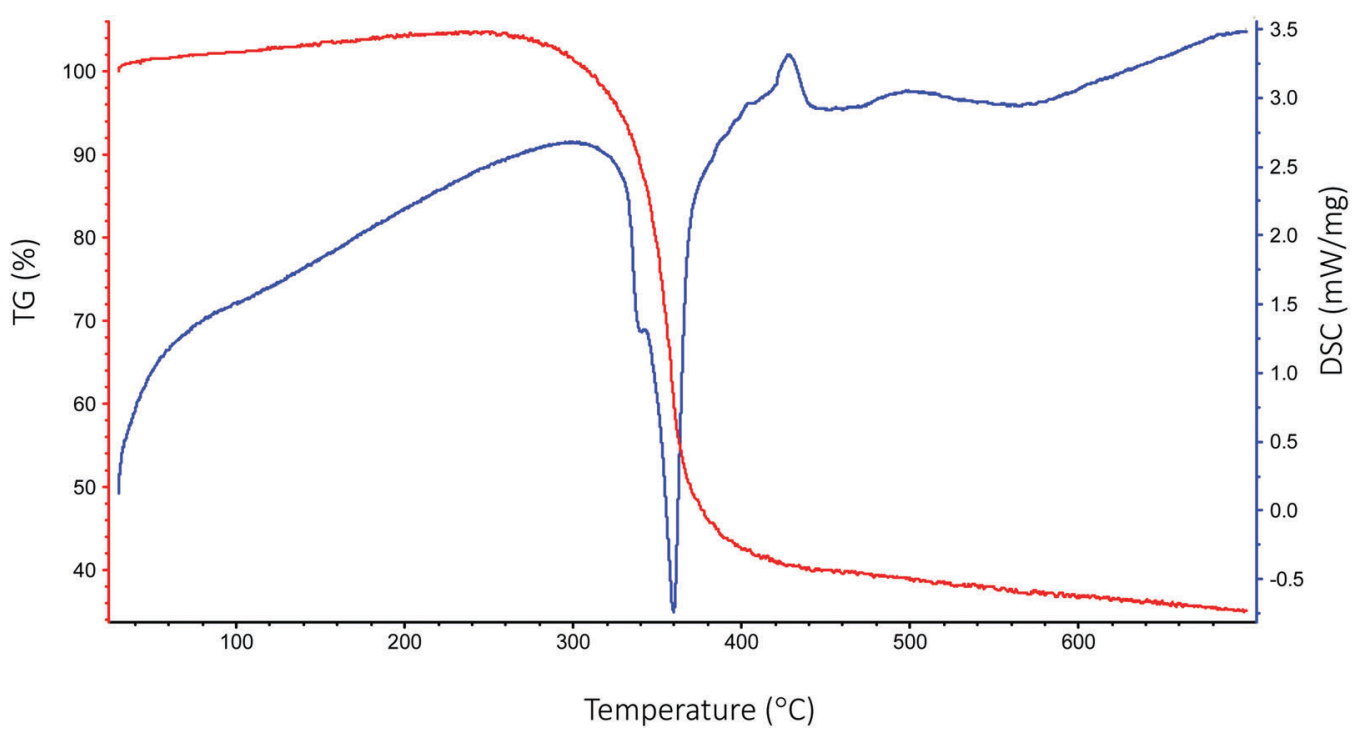

Fig. 5 TGA and DSC curves of the $\left[\mathrm{Sc}(\mathrm{OAc})_{3}\right]$ precursor obtained under helium.

leading through an intermediate $\mathrm{Sc}_{2} \mathrm{O}_{3} \cdot \mathrm{CO}_{2}$ formed at $380{ }^{\circ} \mathrm{C}$ accompanied by an outgassing of $\mathrm{CO}_{2}$, followed by a more gradual outgassing of $\mathrm{CO}_{2}$ at higher temperature. ${ }^{69}$ As for the $\left[\mathrm{Zn}(\mathrm{OAc})_{2}\right]$ precursor, previous study has found that this decomposes in an exothermic reaction around $300{ }^{\circ} \mathrm{C} .{ }^{70}$

Zinc oxide thin films incorporating a range of Sc dopant concentrations were deposited via AACVD from one-pot precursor solutions containing $\mathrm{Zn}$ (II) and $\mathrm{Sc}(\mathrm{III})$ acetates in a methanol-water solvent mixture. The films adhered strongly to the substrate, fully resisting removal by a steel scalpel and by Scotch ${ }^{\circledR}$ tape. Bottom-plate deposition occurred to yield the hexagonal wurtzite films which were visibly transparent and electrically conductive.

The films were analysed for their elemental content via energy-dispersive X-ray spectroscopy (EDX) and X-ray photoelectron spectroscopy (XPS). In the XPS (local and survey scans shown in Fig. S1 in ESI $\dagger$ ), the Sc $2 p$ and $\mathrm{Zn} 2 \mathrm{p}$ environments were probed. The $\mathrm{Zn} 2 \mathrm{p}_{3 / 2}$ peak occurred at $1021.3 \mathrm{eV}$ at low doping levels, agreeing with the $1021.5 \mathrm{eV}$ obtained for $\mathrm{ZnO}$ thin films deposited via AACVD in previous studies. ${ }^{71}$ This blue-shifted slightly to $1021.4 \mathrm{eV}$ for films with bulk Sc doping over 1 at\% relative to $\mathrm{Zn}$ (as determined by EDX). Zn(II) and $\mathrm{Sc}$ (III) were revealed as being the only oxidation states present, with no occurrence of metallic $\mathrm{Zn}(0)$ or $\mathrm{Sc}(0)$. It should be noted that the apparent shoulder at $398 \mathrm{eV}$ occurring adjacent to the $\mathrm{Sc}(\mathrm{III})$ peaks arises from the $\mathrm{N}$ 1s environment.

The efficiency of dopant incorporation for the thin film fabrication was calculated to be $42 \pm 6 \%$ (where $6 \%$ is the standard error), from the bulk Sc: $\mathrm{Zn}$ ratios for all films as obtained from EDX measurements, and the ratio of Sc and Zn precursors in the initial mixtures. It is unsurprising that the quantity of Sc going into the films is consistently lower than 'expected' from the precursor ratios, given that the $\mathrm{Sc}(\mathrm{OAc})_{3}$ precursor decomposes at a higher temperature than $\mathrm{Zn}(\mathrm{OAc})_{2}$; it ought to therefore be expected that at a given deposition temperature, the Zn precursor decomposes faster 
than the Sc precursor, such that the quantity of Sc being incorporated into the film is proportional, but not equivalent to, the ratio of Sc to $\mathrm{Zn}$ precursors in the aerosol. As such, this particular measurement is unique to this synthesis, i.e. in which acetates of $\mathrm{Sc}(\mathrm{III})$ and $\mathrm{Zn}$ (II) are combined in a one-pot water-methanol mixture and deposited under nitrogen onto a $600{ }^{\circ} \mathrm{C}$ barrier glass substrate, etc. The incorporation efficiency of $42 \pm 6 \%$ therefore does not necessarily apply to other methods for Sc-doping of $\mathrm{ZnO}$.

Elemental analysis also indicated a stronger presence of Sc at the surface than in the bulk, as evident in the XPS depth profile shown in Fig. 6 . It is likely that surface Sc(III) corresponds to both substitutional $\mathrm{Sc}_{\mathrm{Zn}}$ dopant environments and an amorphous secondary phase $\mathrm{Sc}_{2} \mathrm{O}_{3}$, which has been observed to nucleate at the $\mathrm{ZnO}$ grain boundaries in previous studies ${ }^{72}$ and which our theoretical model indicates competes with substitutional $\mathrm{Sc}_{\mathrm{Zn}}$ as $\mathrm{Sc}$ loading increases (see Section 2.4.2). Such a nucleation results in a decrease in grain size with increasing dopant concentration due to competing growth processes, which was observed in the SEM (vide infra).

$\mathrm{X}$-ray diffraction measurements of the deposited films were made to obtain their crystallographic characteristics. The diffractograms are shown in Fig. 7. The first thing to notice is that all films show a typical hexagonal wurtzite $\mathrm{ZnO}$ pattern, with $c$-axis preferential orientation along the (002) direction. ${ }^{2}$ There is no apparent secondary crystalline phase, however this does not rule out the presence of small amounts of amorphous $\mathrm{Sc}_{2} \mathrm{O}_{3}$ growing at the grain boundaries. There appears in Fig. 7 to be very little shifting of the (002) peak with increased Sc doping, suggestive of a lack of change in the unit cell parameter. This is to be expected, given that the close matching of the crystallographic radii of $\mathrm{Sc}^{3+}$ and $\mathrm{Zn}^{2+}$ $\left(r_{\mathrm{Sc}^{3+}}=0.745 \AA\right.$ and $\left.r_{\mathrm{Zn}^{2+}}=0.740 \AA\right)$ is likely to exert very little expansive strain in the lattice, ${ }^{73}$ while similar observations have also been made in sol-gel derived ZnO:Sc films in previous study. ${ }^{72}$ This is supported by the lack of any discernible shift of the $\mathrm{E}_{2}$ phonon mode in the Raman arising from doping (see Fig. S3, ESI $\dagger$ ).

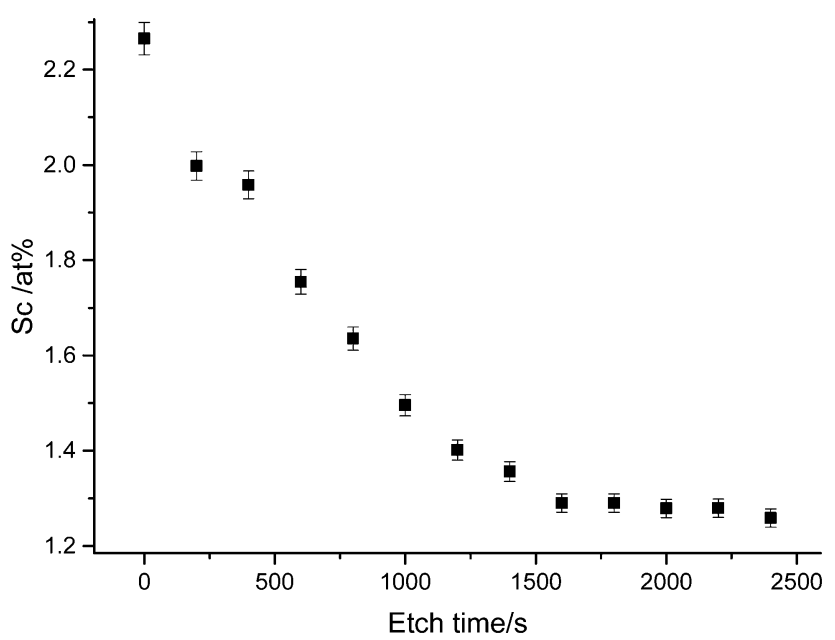

Fig. 6 XPS depth profile of $\mathrm{ZnO}: \mathrm{Sc}$ film illustrating accumulation of Sc(III) species at the film surface. Vertical bars represent the standard deviation of peak area calculations.
Crystallite sizes were estimated from the width of the (002) peak using Scherrer's formula (see eqn (S1) in ESI $\dagger$ ). ${ }^{74}$ A similar trend was observed in the Scherrer-calculated crystallite diameters with increasing Sc loading as seen in the grain sizes in the microscopy. The estimated crystallite diameters, as shown in Fig. 8, decreased monotonically from around $41 \mathrm{~nm}$ for the undoped $\mathrm{ZnO}$ to around $34 \mathrm{~nm}$ for the film containing 1.77 at $\%$ Sc, correlating with a shrink in grain sizes visible from the microscopy (Fig. 9). Crystallite diameters estimated using the Scherrer equation should generally be treated with caution, particularly when the values lie as closely as they do here (i.e. within a $7 \mathrm{~nm}$ range); however, we find that the agreement between XRD and microscopy helps to support this observation, as well as the $75 \%$ mean agreement of the values in the linear fit (the vertical error in Fig. 8 represents the standard deviation of the data points from a linear fit).

Lattice parameters for the $\mathrm{ZnO}: \mathrm{Sc}$ films were calculated using the standard equation for hexagonal lattices (see eqn (S2) in the ESI $\dagger$ ). Since peak shift was insignificant in the doped films, there was little significant change in the calculated unit cell parameters, which in the undoped $\mathrm{ZnO}$ film were calculated using the (002) and (101) peaks as $a=3.251 \AA$ and $c=5.202 \AA$. These are in strong agreement with accepted literature experimental values of $a=3.2501 \AA$ and $c=5.2071 \AA^{75}$

The texture coefficient $(\mathrm{TC}(h k l))$ for each of the six diffraction peaks in the ZnO:Sc films was calculated from their intensities relative to eachother and to the standard powder pattern (ICSD 29272), as per eqn (S3) in the ESI. $\dagger$ The calculated TC $(h k l)$ are plotted in Fig. S2 in the ESI $\nmid$ against the bulk Sc concentrations in the ZnO:Sc films as obtained by EDX. Although a trend is not clearly apparent for the variation in $\mathrm{TC}(h k l)$ with increased doping (as likewise observed by other authors for $\mathrm{ZnO}: \mathrm{Sc}^{76}$ ), there is a clear preference for $c$-axis orientation as indicated by the consistently strong texture coefficient for the (002) reflection.

Scanning electron microscopy (SEM) of the films, shown in Fig. 9, revealed a clear trend of decreasing grain diameter with increased Sc loading. Thicknesses of the films were measured from the side-on micrographs to be within the range 320-640 nm. From the pure $\mathrm{ZnO}$ micrograph it is apparent that the $\mathrm{ZnO}$ is growing in a platelet-like morphology, similar to that observed in ZnO:Al films grown via AACVD in previous study. ${ }^{71}$ As Sc loading increases, this morphology is retained by the $\mathrm{ZnO}$ crystallites though there is the distinct appearance of a secondary phase forming at the fringes of the ZnO. As well as having been predicted by our model (see eqn (3)), previous studies suggest that this is probably the amorphous secondary phase $\mathrm{Sc}_{2} \mathrm{O}_{3}$, which grows in competition with the doped ZnO:Sc phase. ${ }^{77}$ The competitive growth of this secondary phase is likely the cause for the reduction in $\mathrm{ZnO}: \mathrm{Sc}$ grain and crystallite size.

Hall effect measurements were carried out on the films to determine their electrical resistivities and their charge carrier densities and mobilities. It was found that 1.0 at\% Sc: $Z n$ in the film was the optimum doping level, exhibiting the lowest resistivity recorded at $\rho=1.2 \times 10^{-3} \Omega \mathrm{cm}$, in contrast to $\rho=1.3 \times 10^{-1} \Omega \mathrm{cm}$ for the undoped $\mathrm{ZnO}$ film, which appears to be the lowest resistivity recorded for a $\mathrm{ZnO}$ :Sc film synthesised on glass via a 


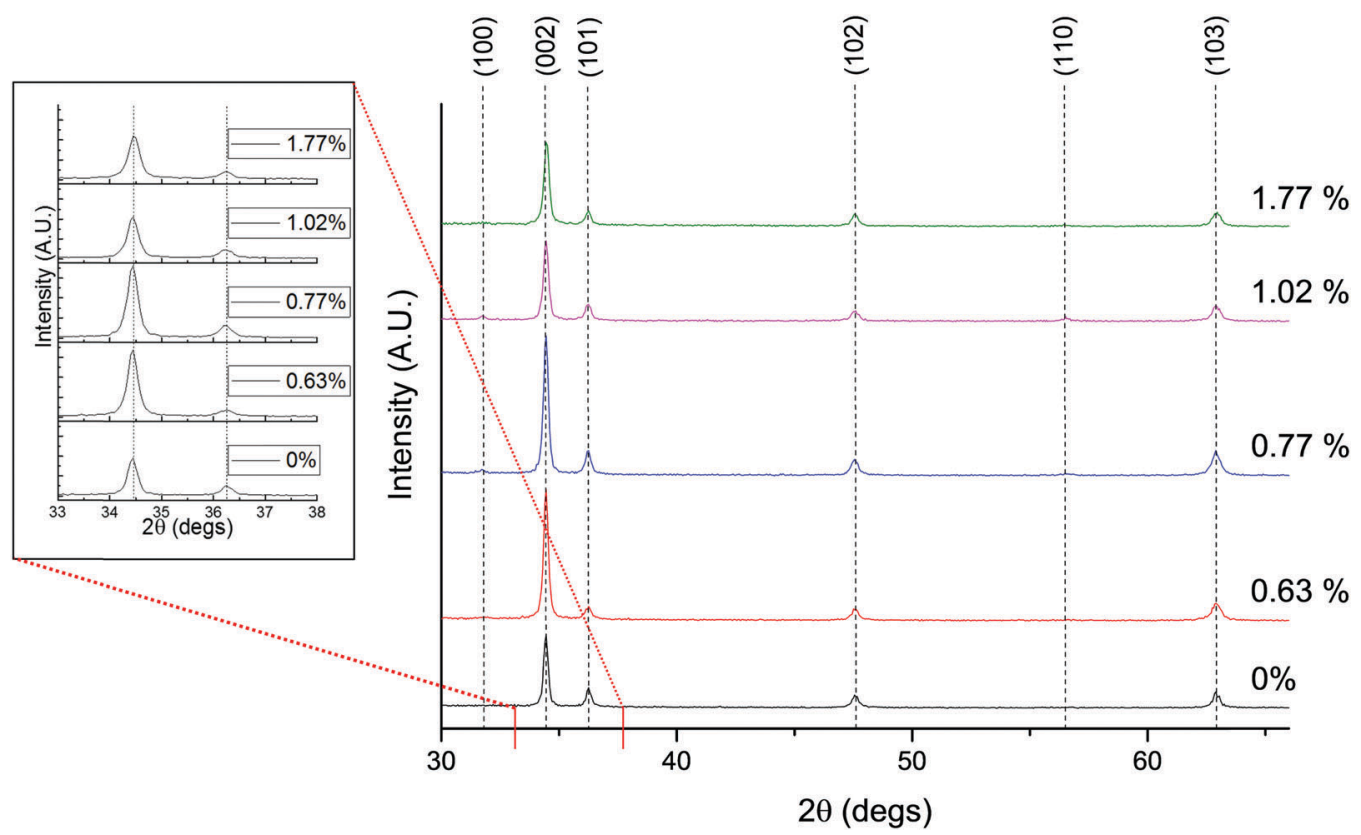

Fig. 7 X-ray diffractograms of ZnO:Sc containing varying at\% Sc relative to $\mathrm{Zn}$, and (inset) close-up on the shift of the (002) and (101) peaks.

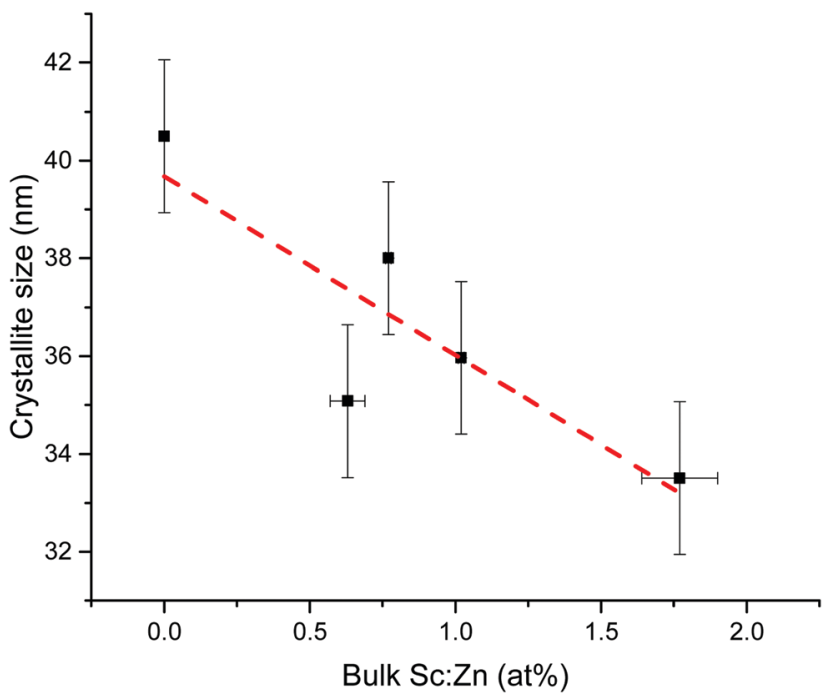

Fig. 8 Plot showing effect on crystallite diameter of increased Sc doping in $\mathrm{ZnO}$, as calculated using the Scherrer formula. Sc abundance is expressed relative to $\mathrm{Zn}$ in the films. Coefficient of determination $R^{2}=0.75$.

chemical deposition route. The same film exhibited $\rho=2.0 \times$ $10^{-3} \Omega \mathrm{cm}$ after having spent 12 months stored under ambient conditions, demonstrating excellent atmospheric stability compared to the infamously unstable Al-doped $\mathrm{ZnO} .{ }^{78}$ The dramatic reduction in resistivity between undoped and Sc-doped $\mathrm{ZnO}$ was accompanied by an increase in the carrier density and mobility from $n=2.1 \times 10^{19} \mathrm{~cm}^{-3}$ and $\mu=2.3 \mathrm{~cm}^{2} \mathrm{~V}^{-1} \mathrm{~s}^{-1}$ to $n=7.2 \times$ $10^{20} \mathrm{~cm}^{-3}$ and $\mu=7.5 \mathrm{~cm}^{2} \mathrm{~V}^{-1} \mathrm{~s}^{-1}$, respectively. Further doping effected a reverse of these properties, such that a slight increase in resistivity and reductions in the charge carrier densities and mobilities were observed (see Fig. 10). A similar pattern was previously observed in $\mathrm{ZnO}$ :Sc films deposited via magnetron sputtering. ${ }^{11}$ This is a common pattern for extrinsic n-type doping of semiconductors. The carrier density pattern is typically attributed to a trade-off between the increasing number of charge carriers being introduced at low dopant levels, with a reduction in carrier density occurring beyond some critical doping point on account of an increasing concentration of compensating vacancy $V_{\mathrm{Zn}}$ defects arising from their shrinking formation energy accompanied by a rising formation energy for $\mathrm{Sc}_{\mathrm{Zn}}$, as supported by our calculations (see Fig. 3) and previous work. ${ }^{32}$ In the case of mobility, the reduction occurs at higher doping levels due to an increase in the probability of propagating electrons being scattered at dopant sites and a shrinking crystallite size. The cause for the initial increase in mobility is unclear, though previous ZnO:Al doping study has noted an increase in the carrier mean free path at low dopant levels, in spite of a shrinking crystallite diameter relative to the undoped material. ${ }^{79}$ The ionised impurity scattering is typically the dominant scattering mechanism at higher dopant levels $\left(n=10^{20}-10^{21} \mathrm{~cm}^{-3}\right)$, though grain boundary scattering becomes more significant at low dopant levels $\left(n=10^{19}-10^{20} \mathrm{~cm}^{-3}\right) \cdot{ }^{80} \mathrm{ZnO}$ films grown previously via AACVD have yielded closely comparable mobilities $\left(\mu=9.7 \mathrm{~cm}^{2} \mathrm{~V}^{-1} \mathrm{~s}^{-1}\right.$ in $\mathrm{ZnO}: \mathrm{Al}, \mathrm{F})^{71}$

It is also interesting to note that those nominally undoped ZnO films, deposited also via AACVD but from a diethyl zinc precursor as opposed to the zinc acetate precursor used here, exhibit low resistivities similar to those measured for Al-doped ZnO in the same study $\left(\rho_{\text {Zno }} \approx \rho_{\text {ZnO:Al }}=2.2 \times 10^{-3} \Omega \mathrm{cm}\right),{ }^{71}$ while undoped ZnO deposited here from zinc acetate has $\rho=1.3 \times$ $10^{-1} \Omega \mathrm{cm}$. It is often argued that conductivity in nominally undoped $\mathrm{ZnO}$ originates from nonstoichiometry which gives rise to electron-donating oxygen vacancies $V_{\mathrm{O}}$ and interstitial $\mathrm{Zn}_{\text {int }}$ in the ZnO. ${ }^{1,32}$ However, since our calculations (and others ${ }^{\text {,30 }}$ ) 

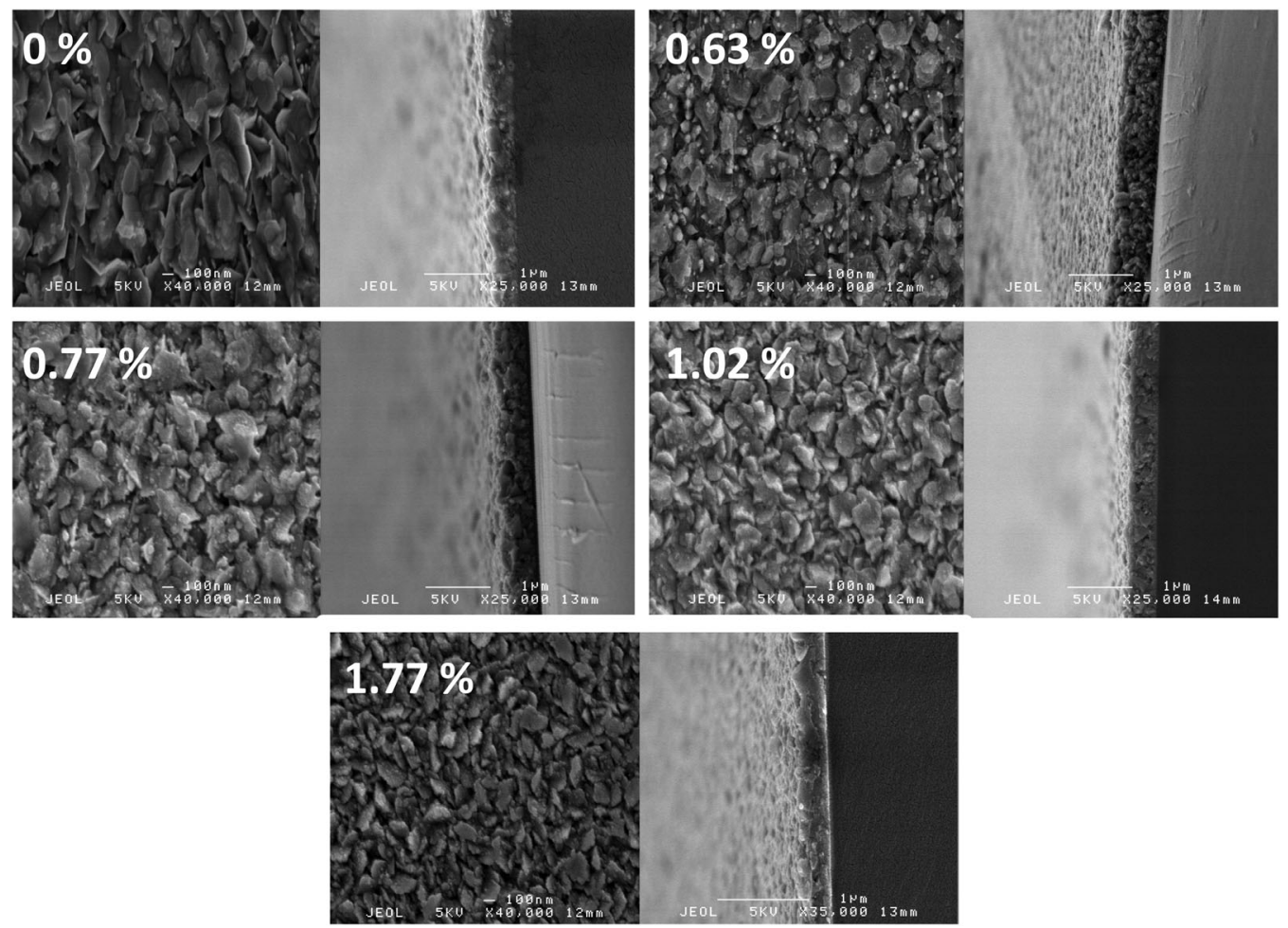

Fig. 9 Top-down and side-on scanning electron micrographs of increasingly Sc-doped ZnO samples, expressed in at\% relative to $\mathrm{Zn}$.

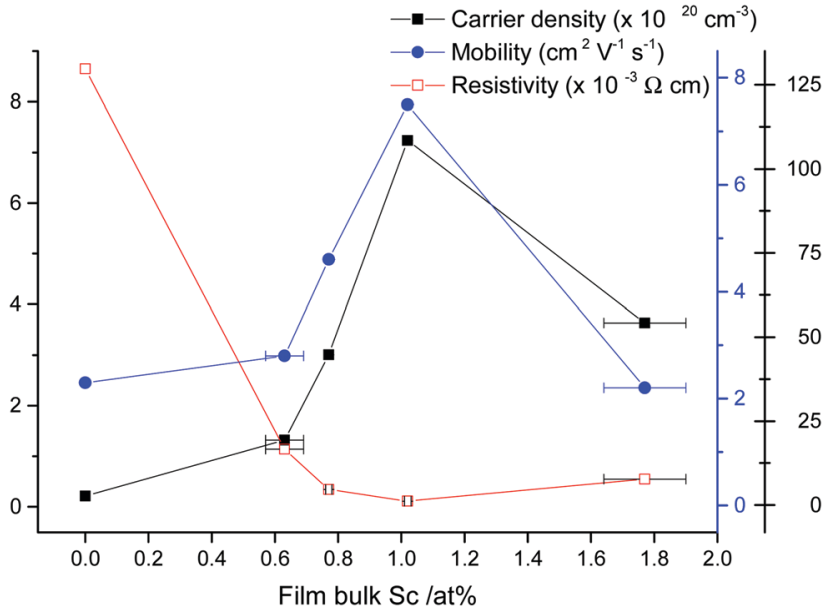

Fig. 10 Electrical properties for SZO films as obtained by Hall effect measurements.

suggest that $V_{\mathrm{O}}$ is a relatively deep donor (see Section 3.1) while $\mathrm{Zn}_{\text {int }}$ has been shown to have a relatively high formation energy, ${ }^{30}$ we consider that this effect is due to a difference in the degree of hydrogen doping of the $\mathrm{ZnO}$ by interstitial $\mathrm{H}_{\text {int }}$, a shallow donor which should therefore be the dominant donor defect in these films. ${ }^{30,65,66}$ First-principles work by Oba et al. ${ }^{30}$ suggests that such defects are likewise preferentially formed under an oxygen-poor deposition environment, which helps to rationalise the trend that lower resistivities are observed in nominally undoped $\mathrm{ZnO}$ films deposited from the oxygen-poor diethyl zinc precursor $\left(\left[\mathrm{Zn}\left(\mathrm{CH}_{2} \mathrm{CH}_{3}\right)_{2}\right]\right),{ }^{71}$ when compared with those obtained from the zinc acetate precursor $\left(\left[\mathrm{Zn}\left(\mathrm{OCOCH}_{3}\right)_{2}\right]\right)$, which is richer in oxygen, in the present work. It should be noted that overall, we consider the deposition environment used in the present study to be largely oxygen-poor, having been carried out under inert gas with the only sources of oxygen for oxide formation being the molecular acetate precursors and in the solvents present.

UV-visible transmission measurements of the doped ZnO:Sc samples are plotted in Fig. 11. The films were visibly transparent and uncoloured. It is evident that an increased level of doping leads to a reduction in the transmittance of the films in the infrared, resulting in a minimum transmittance occurring in the near-infrared at $2500 \mathrm{~nm}$ in the ZnO:Sc film with the highest charge carrier density. This is a commonly observed phenomenon in n-type TCOs and is related to an increasing low-energy surface plasmon resonance (SPR) effect at high carrier densities, where increased charge carrier density is directly correlated with increased infrared reflectivity. ${ }^{5} \mathrm{~A}$ further increase in Sc doping beyond the optimum level in the ZnO:Sc was observed in the Hall measurements to effect a reduction in the charge carrier density, which (as expected) is directly observed to reduce the infrared reflectivity. There is a high degree of transmission in the visible range $(400-750 \mathrm{~nm})$ in all films, with $88 \%$ visible transmission in the most electrically conductive sample and the highest visible transmission occurring in pure $\mathrm{ZnO}$ at $91 \%$. The doping has the effect of marginally reducing the visible transmission, as expected according to the principle of free carrier absorption (FCA). ${ }^{6}$ 


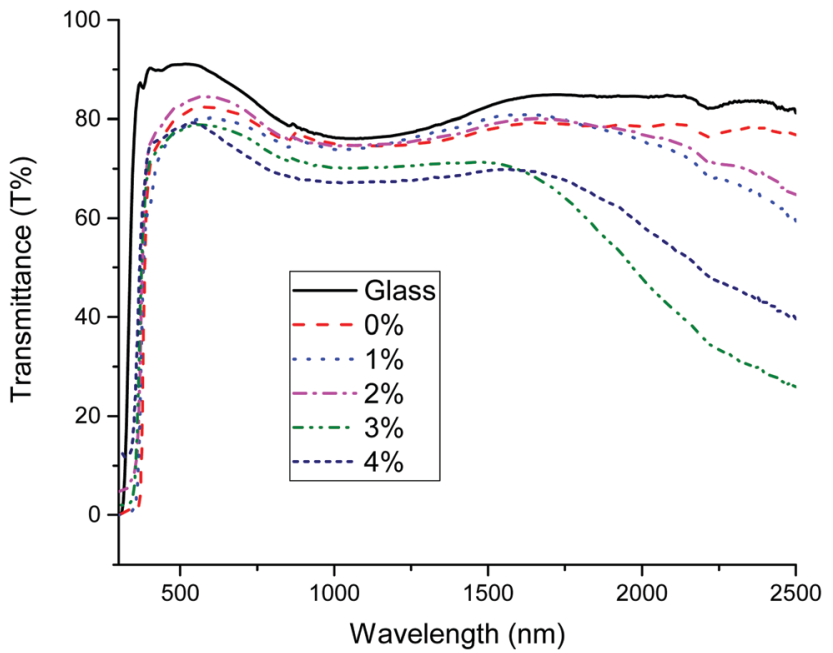

Fig. 11 UV-visible transmission spectra of plain glass and increasingly Scdoped $\mathrm{ZnO}$ films.

Optical band gaps of thin film TCOs are often estimated using the Tauc method, in which a plot is constructed from optical absorption data near to the absorption edge of the material (here appearing around $380 \mathrm{~nm}$ ). Where $\alpha$ is the optical absorption coefficient, $h$ is Planck's constant and $\nu$ is the incident photon frequency, for a direct band gap material such as ZnO a plot of $(\alpha h \nu)^{2} v s$. $h \nu$ is drawn, such that the steepest gradient occurring along the absorption edge is linearly extrapolated to the $x$-intercept to find the film's optical band gap $E_{\mathrm{g}}^{\text {opt }}{ }^{81}$ However, it is generally found that band gaps estimated using the Tauc method for degenerate polycrystalline semiconductors are underestimated when compared with band gaps found using other methods such as spectroscopic ellipsometry (SE). For instance, applying the uncorrected Tauc method here yields a band gap of $E_{\mathrm{g}}^{\mathrm{opt}}=3.28 \mathrm{eV}$ for nominally undoped $\mathrm{ZnO}$, which agrees with numerous previous experimental Tauc band gaps for undoped $\mathrm{ZnO}$ of $E_{\mathrm{g}}^{\mathrm{opt}}=3.27 \pm 0.02 \mathrm{eV} .^{76,82,83}$ However, SE data suggests that $\mathrm{ZnO}$ thin films should have a band gap of $E_{\mathrm{g}}^{\mathrm{opt}}=3.37 \mathrm{eV}{ }^{84}$ In a recent discussion on this dilemma, Dolgonos et al. suggest that the issue arises from the fact that the Tauc method was originally developed for estimation of the band gap of amorphous $\mathrm{Ge}$, a nondegenerate semiconductor. ${ }^{85}$ Aside from the fact that assumptions regarding localisation of energy states in an amorphous material might not necessarily hold for a polycrystalline material (which instead contains far greater long-range order), accurate extraction of $E_{g}$ information from absorption data is further complicated by broadening of initial and final electron-hole pair states upon photon absorption arising from time-dependent perturbation theory effects. Dolgonos et al. argue that a broadening term $\Gamma$ for this effect can be estimated from optical absorption data, such that the separation of the $x$-intercepts of tangents drawn from $\alpha$ and $\alpha^{2}$ curves gives $\frac{\pi}{4} \Gamma$, which can be added to the Taucestimated band gap to give a more accurate, corrected estimate for the band gap. ${ }^{85}$ This correction was carried out on absorption data in the present work, in order to obtain more accurate band

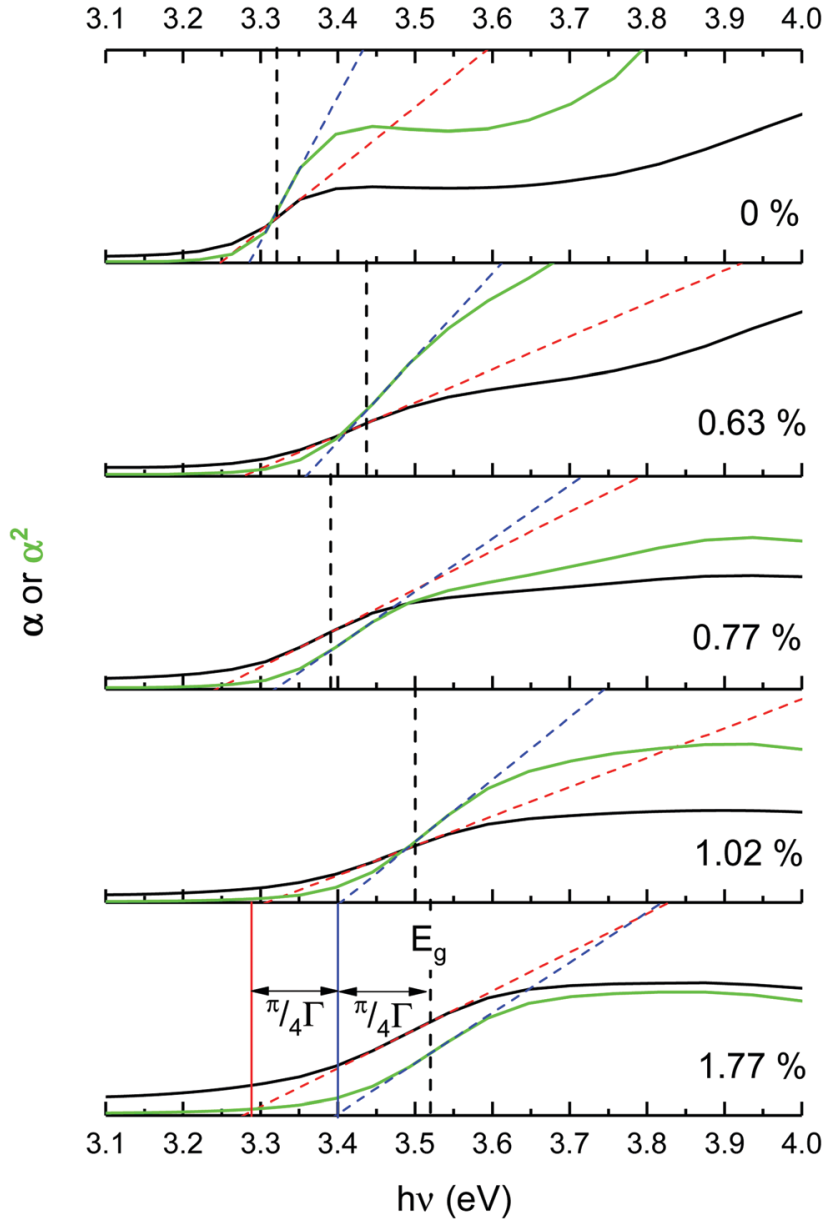

Fig. 12 Corrected Tauc optical band gap plots calculated from UV/vis transmission spectra at the absorption edge, for Sc-doped $\mathrm{ZnO}$ films containing increasing amounts of bulk Sc (expressed relative to $\mathrm{Zn}$ in at\%).

gap estimates for degenerate ZnO:Sc (see Fig. 12). Assuming a linear relationship between increased Sc content and optical

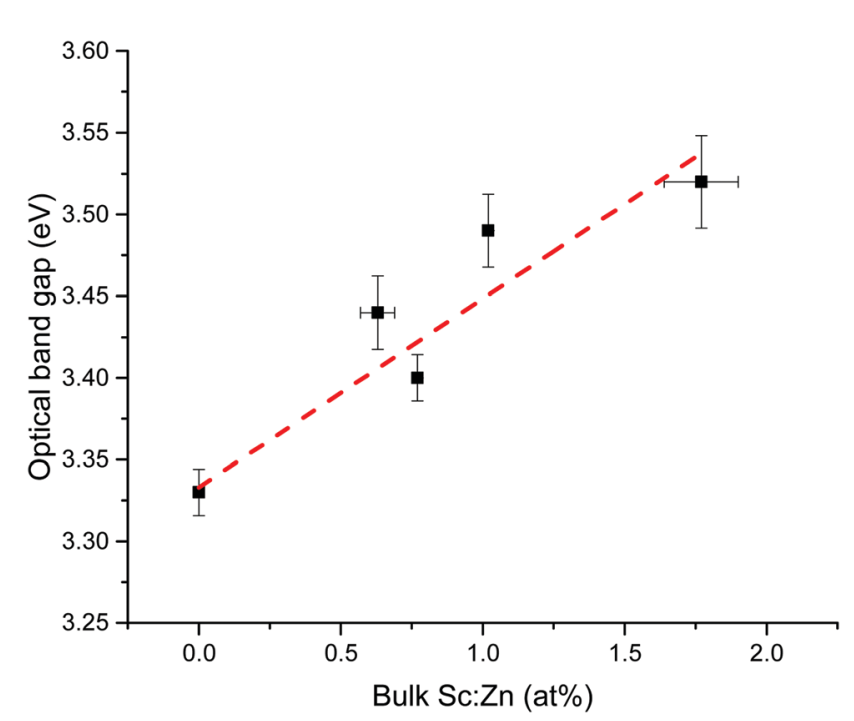

Fig. 13 Linear trend in corrected Tauc optical band gap vs. amount of bulk Sc (expressed relative to $\mathrm{Zn}$ in at\%). 
band gap (coefficient of determination $R^{2}=0.81$ ), ${ }^{86}$ at $0 \% \mathrm{Sc}$ doping (i.e. for pure $\mathrm{ZnO}$ ) this correction yields $E_{\mathrm{g}}^{\mathrm{opt}}=3.34 \pm$ $0.03 \mathrm{eV}$, while the most electrically conductive $\mathrm{ZnO}: \mathrm{Sc}$ sample at 1.02 at\% bulk Sc:Zn has $E_{\mathrm{g}}^{\text {opt }}=3.45 \pm 0.03 \mathrm{eV}$ (see Fig. 13). Such an observation would be consistent with the Moss-Burstein bandgap widening principle which attributes this effect to an increasing occupation of the lowest states of the CB with increased doping. ${ }^{6}$ The same trend has been observed previously for $\mathrm{ZnO}$ :Sc thin films. ${ }^{4}$ These estimates are significantly closer to the experimental values obtained from SE (3.37 eV for $\mathrm{ZnO}),{ }^{30}$ while we acknowledge that error in the corrected Tauc method is still inherent due to the necessary extrapolation step. Aside from this, variation in calculated $\mathrm{ZnO}$ band gaps arises between studies from effects such as varying degrees of crystallinity and degeneracy in nominally undoped $\mathrm{ZnO}$ films due to intrinsic n-type doping.

\section{Conclusions}

A computational model for Sc doping of $\mathrm{ZnO}$ has been constructed using hybrid density functional theory calculations alongside a synthetic experimental study of ZnO:Sc thin films. Strong correlation between the theoretical and experimental results has offered an insight into the defect landscape of Sc-doped $\mathrm{ZnO}$ and helped to rationalise the trends observed in the Hall effect measurements, while showing that substitutional $\mathrm{Sc}\left(\mathrm{Sc}_{\mathrm{Zn}}\right)$ acts as a shallow donor in $\mathrm{ZnO}$ and indicating that oxygen-poor deposition conditions are necessary for achieving efficient n-type doping. Transparent and n-type conducting Sc-doped ZnO thin films were successfully deposited via a one-pot aerosol-assisted chemical vapour deposition onto silica barrier glass substrates. It can therefore be concluded that the deposition under nitrogen from acetates of $\mathrm{Zn}$ (II) and $\mathrm{Sc}$ (III) provides sufficiently O-poor growth conditions for efficient $\mathrm{Sc}_{\mathrm{Zn}}$ donor doping. Future experimental work might seek to explore the $\mathrm{ZnO}$ :Sc growth environment further by tweaking the balance of $\mathrm{Zn}$ and $\mathrm{O}$ abundance during film growth. A range of films containing various Sc quantities were synthesised in order to demonstrate growth behaviours and optimal deposition conditions. All syntheses were carried out in a single-step deposition from an alcoholic solution of the organometallic salt precursors, using a range of Sc:Zn precursor ratios between 0.0 and $4.0 \mathrm{~mol} \%$. Optimal electrical properties were obtained in the film containing 1.0 at $\%$ bulk Sc relative to $\mathrm{Zn}$; this film exhibited the lowest resistivity at $\rho=1.2 \times 10^{-3} \Omega \mathrm{cm}$, in contrast to $\rho=1.3 \times 10^{-1} \Omega \mathrm{cm}$ for the undoped $\mathrm{ZnO}$ film. This appears to be the lowest resistivity recorded for a ZnO:Sc film on glass via a chemical deposition route, and indeed the only reported instance of electrically conductive $\mathrm{ZnO}: \mathrm{Sc}$ having been deposited via chemical vapour deposition. That same film also had carrier density $n=7.2 \times$ $10^{20} \mathrm{~cm}^{-3}$ and electron mobility $\mu=7.5 \mathrm{~cm}^{2} \mathrm{~V}^{-1} \mathrm{~s}^{-1}$, and was highly transparent in the visible with $88 \%$ transmission (400-750 nm). Storage of the sample for 12 months under ambient conditions effected only a slight increase of resistivity, to $\rho=2.0 \times 10^{-3} \Omega \mathrm{cm}$, suggesting excellent atmospheric stability. Increased Sc doping led to reduced $\mathrm{ZnO}$ grain and crystallite sizes and widened band gaps, with $E_{\mathrm{g}}^{\mathrm{opt}}=3.45 \pm$ $0.03 \mathrm{eV}$ in the most conductive sample and $E_{\mathrm{g}}^{\mathrm{opt}}=3.34 \pm 0.03 \mathrm{eV}$ in nominally undoped $\mathrm{ZnO}$, as estimated using a corrected Tauc method. No observable shift in unit cell dimensions occurred with doping, as attributed to the close matching of the Sc(III) and $\mathrm{Zn}$ (II) ionic radii. In summary, in spite of having thus far received relatively little attention in the materials research community, Sc-doped $\mathrm{ZnO}$ has been shown to be a highly promising transparent conducting oxide warranting further investigation, for which it is hoped that this paper will serve as a useful reference.

\section{Acknowledgements}

Thanks are due to Dr Chris Blackman, Dr Steve Firth and Sultan Ben Jaber for assistance with Raman spectroscopy. The authors would also like to acknowledge and thank NSG Pilkington Glass Ltd. and the EPSRC for studentship funding (S. C. D.) through the $\mathrm{M}^{3} \mathrm{~S}$ Doctoral Training Centre (grant EP/G036675) and also for grant EP/N01572X/1. This work made use of the ARCHER UK National Supercomputing Service (http://www.archer.ac.uk) via our membership of the UK's HEC Materials Chemistry Consortium, which is also funded by the EPSRC (EP/L000202). The UCL Legion and Grace HPC Facilities (Legion@UCL and Grace@UCL) were also used in the completion of this work.

\section{References}

1 R. Pandey, S. Yuldashev, H. D. Nguyen, H. C. Jeon and T. W. Kang, Curr. Appl. Phys., 2012, 12, S56-S58.

2 R. S. Ajimsha, A. K. Das, P. Misra, M. P. Joshi, L. M. Kukreja, R. Kumar, T. K. Sharma and S. M. Oak, J. Alloys Compd., 2015, 638, 55-58.

3 H. M. Yates, J. M. Gaskell, M. E. Thomson, D. W. Sheel, B. Delaup and M. Morales-Masis, Thin Solid Films, 2015, 590, 260-265.

4 R. Sharma, K. Sehrawat and R. M. Mehra, Curr. Appl. Phys., 2010, 10, 164-170.

5 N. Noor, C. K. T. Chew, D. S. Bhachu, M. R. Waugh, C. J. Carmalt and I. P. Parkin, J. Mater. Chem. C, 2015, 3, 9359-9368.

6 S. C. Dixon, D. O. Scanlon, C. J. Carmalt and I. P. Parkin, J. Mater. Chem. C, 2016, 419, 462-465.

7 U. Betz, M. Kharrazi Olsson, J. Marthy, M. F. Escolá and F. Atamny, Surf. Coat. Technol., 2006, 200, 5751-5759.

8 European Commission, Report on critical raw materials for the EU, Report of the Ad hoc Working Group on defining critical raw materials, 2014.

9 G. Hautier, A. Miglio, D. Waroquiers, G.-M. Rignanese and X. Gonze, Chem. Mater., 2014, 26, 5447-5458.

10 D. S. Bhachu, D. O. Scanlon, G. Sankar, T. D. Veal, R. G. Egdell, G. Cibin, A. J. Dent, C. E. Knapp, C. J. Carmalt and I. P. Parkin, Chem. Mater., 2015, 27, 2788-2796.

11 T. Minami, T. Yamamoto and T. Miyata, Thin Solid Films, 2000, 366, 63-68. 
12 P. Marchand, I. A. Hassan, I. P. Parkin and C. J. Carmalt, Dalton Trans., 2013, 42, 9406.

13 S. C. Dixon, W. J. Peveler, N. Noor, J. C. Bear and I. P. Parkin, RSC Adv., 2016, 6, 31146-31152.

14 M. G. Nolan, J. A. Hamilton, S. O’Brien, G. Bruno, L. Pereira, E. Fortunato, R. Martins, I. M. Povey and M. E. Pemble, J. Photochem. Photobiol., A, 2011, 219, 10-15.

15 G. Kresse and J. Hafner, Phys. Rev. B: Condens. Matter Mater. Phys., 1993, 47, 558-561.

16 G. Kresse and J. Hafner, Phys. Rev. B: Condens. Matter Mater. Phys., 1994, 49, 14251-14269.

17 G. Kresse, J. Furthmu, J. Furthmüller, G. Kresse and J. Furthmu, Phys. Rev. B: Condens. Matter Mater. Phys., 1996, 54, 11169.

18 G. Kresse and J. Furthmüller, Comput. Mater. Sci., 1996, 6, 15-50.

19 P. E. Blochl, Phys. Rev. B: Condens. Matter Mater. Phys., 1994, 50, 17953-17979.

20 J. Heyd, G. E. Scuseria and M. Ernzerhof, J. Chem. Phys., 2003, 118, 8207-8215.

21 D. O. Scanlon and G. W. Watson, J. Mater. Chem., 2012, 22, 25236.

22 A. M. Ganose and D. O. Scanlon, J. Mater. Chem. C, 2016, 4, 1467-1475.

23 J. Buckeridge, K. T. Butler, C. R. A. Catlow, A. J. Logsdail, D. O. Scanlon, S. A. Shevlin, S. M. Woodley, A. A. Sokol and A. Walsh, Chem. Mater., 2015, 27, 3844-3851.

24 B. A. D. Williamson, J. Buckeridge, J. Brown, S. Ansbro, R. G. Palgrave and D. O. Scanlon, Chem. Mater., 2017, 29, 2402-2413.

25 D. O. Scanlon, A. Regoutz, R. G. Egdell, D. J. Morgan and G. W. Watson, Appl. Phys. Lett., 2013, 103, 262108.

26 D. S. Bhachu, S. Sathasivam, G. Sankar, D. O. Scanlon, G. Cibin, C. J. Carmalt, I. P. Parkin, G. W. Watson, S. M. Bawaked, A. Y. Obaid, S. Al-Thabaiti and S. N. Basahel, Adv. Funct. Mater., 2014, 24, 5075-5085.

27 D. O. Scanlon, J. Buckeridge, C. R. A. Catlow and G. W. Watson, J. Mater. Chem. C, 2014, 2, 3429.

28 D. O. Scanlon and G. W. Watson, Chem. Mater., 2009, 21, 5435-5442.

29 D. O. Scanlon, C. W. Dunnill, J. Buckeridge, S. A. Shevlin, A. J. Logsdail, S. M. Woodley, C. R. A. Catlow, M. J. Powell, R. G. Palgrave, I. P. Parkin, G. W. Watson, T. W. Keal, P. Sherwood, A. Walsh and A. A. Sokol, Nat. Mater., 2013, 12, 798-801.

30 F. Oba, A. Togo, I. Tanaka, J. Paier and G. Kresse, Phys. Rev. B: Condens. Matter Mater. Phys., 2008, 77, 245202.

31 A. Walsh, J. L. F. Da Silva, Y. Yan, M. M. Al-Jassim and S. Wei, Phys. Rev. B: Condens. Matter Mater. Phys., 2009, 79, 73105.

32 S. Lany and A. Zunger, Phys. Rev. Lett., 2007, 98, 45501.

33 A. Janotti, J. B. Varley, P. Rinke, N. Umezawa, G. Kresse and C. G. Van De Walle, Phys. Rev. B: Condens. Matter Mater. Phys., 2010, 81, 85212.

34 J. L. Lyons, A. Janotti and C. G. Van De Walle, J. Appl. Phys., 2014, 115, 12014.

35 P. Deák, B. Aradi and T. Frauenheim, Phys. Rev. B: Condens. Matter Mater. Phys., 2011, 83, 1-7.
36 J. B. Varley, A. Janotti and C. G. Van De Walle, Adv. Mater., 2011, 23, 2343-2347.

37 H. Chen and J. A. Dawson, J. Phys. Chem. C, 2015, 119, 15890-15895.

38 H. A. Huy, B. Aradi, T. Frauenheim and P. Deák, Phys. Rev. B: Condens. Matter Mater. Phys., 2011, 83, 1-7.

39 F. Oba, M. Choi, A. Togo, A. Seko and I. Tanaka, J. Phys.: Condens. Matter, 2010, 22, 384211.

40 S. J. Clark, J. Robertson, S. Lany and A. Zunger, Phys. Rev. B: Condens. Matter Mater. Phys., 2010, 81, 1-5.

41 D. O. Scanlon, Phys. Rev. B: Condens. Matter Mater. Phys., 2013, 87, 161201.

42 S. Lany and A. Zunger, Phys. Rev. B: Condens. Matter Mater. Phys., 2008, 78, 17-20.

43 H. Peng, D. O. Scanlon, V. Stevanovic, J. Vidal, G. W. Watson and S. Lany, Phys. Rev. B: Condens. Matter Mater. Phys., 2013, 88, 1-7. 44 P. A. Schultz, Phys. Rev. Lett., 2006, 96, 246401.

45 D. C. Reynolds, D. C. Look, B. Jogai, C. W. Litton, G. Cantwell and W. C. Harsch, Phys. Rev. B: Condens. Matter Mater. Phys., 1999, 60, 2340-2344.

46 H. Karzel, W. Potzel, M. Köfferlein, W. Schiessl, M. Steiner, U. Hiller, G. M. Kalvius, D. W. Mitchell, T. P. Das, P. Blaha, K. Schwarz and M. P. Pasternak, Phys. Rev. B: Condens. Matter Mater. Phys., 1996, 53, 11425-11438.

47 S. Desgreniers, Phys. Rev. B: Condens. Matter Mater. Phys., 1998, 58, 14102-14105.

48 R. R. Reeber, J. Appl. Phys., 1970, 41, 5063-5066.

49 A. Janotti and C. G. Van De Walle, Phys. Rev. B: Condens. Matter Mater. Phys., 2007, 76, 1-22.

50 C. G. Van De Walle and J. Neugebauer, J. Appl. Phys., 2004, 95, 3851-3879.

51 N. D. M. Hine, K. Frensch, W. M. C. Foulkes and M. W. Finnis, Phys. Rev. B: Condens. Matter Mater. Phys., 2009, 79, 24112.

52 R. M. Nieminen, Modell. Simul. Mater. Sci. Eng., 2009, 17, 84001 .

53 S. T. Murphy and N. D. M. Hine, Phys. Rev. B: Condens. Matter Mater. Phys., 2013, 87, 1-18.

54 C. Freysoldt, J. Neugebauer and C. G. Van De Walle, Phys. Rev. Lett., 2009, 102, 1-4.

55 M. Lorenz, C. Schmidt, G. Benndorf, T. Böntgen, H. Hochmuth, R. Böttcher, A. Pöppl, D. Spemann and M. Grundmann, J. Phys. D: Appl. Phys., 2013, 46, 65311.

56 O. Mryasov and A. Freeman, Phys. Rev. B: Condens. Matter Mater. Phys., 2001, 64, 2-4.

57 S. K. Vasheghani Farahani, T. D. Veal, J. J. Mudd, D. O. Scanlon, G. W. Watson, O. Bierwagen, M. E. White, J. S. Speck and C. F. McConville, Phys. Rev. B: Condens. Matter Mater. Phys., 2014, 90, 1-9.

58 K. J. Button, D. R. Cohn, M. Von Ortenbert, B. Lax, E. Mollwo and R. Helbig, Phys. Rev. Lett., 1972, 28, 1637-1639.

59 F. Oba, S. R. Nishitani, S. Isotani, H. Adachi and I. Tanaka, J. Appl. Phys., 2001, 90, 824.

60 A. Janotti and C. G. Van De Walle, J. Cryst. Growth, 2006, 287, 58-65.

61 S. B. Zhang, S.-H. Wei and A. Zunger, Phys. Rev. B: Condens. Matter Mater. Phys., 2001, 63, 75205. 
62 X. J. Wang, L. S. Vlasenko, S. J. Pearton, W. M. Chen and I. A. Buyanova, J. Phys. D: Appl. Phys., 2009, 42, 175411.

63 D. M. Hofmann, D. Pfisterer, J. Sann, B. K. Meyer, R. TenaZaera, V. Munoz-Sanjose, T. Frank and G. Pensl, Appl. Phys. A: Mater. Sci. Process., 2007, 88, 147-151.

64 L. S. Vlasenko, Appl. Magn. Reson., 2010, 39, 103-111.

65 C. G. Van de Walle, Phys. Rev. Lett., 2000, 85, 1012-1015.

66 S. F. J. Cox, E. A. Davis, S. P. Cottrell, P. J. C. King, J. S. Lord, J. M. Gil, H. V. Alberto, R. C. Vilão, J. Piroto Duarte, N. Ayres de Campos, A. Weidinger, R. L. Lichti and S. J. C. Irvine, Phys. Rev. Lett., 2001, 86, 2601-2604.

67 S. Lany and A. Zunger, Phys. Rev. B: Condens. Matter Mater. Phys., 2009, 80, 1-5.

68 K. C. Patil, G. V. Chandrashekhar, M. V. George and C. N. R. Rao, Can. J. Chem., 1968, 46, 257-265.

69 M. Yoshio and S. Shunsuke, J. Inorg. Nucl. Chem., 1980, 42, 299-301.

70 Y. Yang, H. Chen, B. Zhao and X. Bao, J. Cryst. Growth, 2004, 263, 447-453.

71 S. D. Ponja, S. Sathasivam, I. P. Parkin and C. J. Carmalt, RSC Adv., 2014, 4, 49723-49728.

72 J. Chen, D. Chen, J. He, S. Zhang and Z. Chen, Appl. Surf. Sci., 2009, 255, 9413-9419.

73 K.-C. Peng, J.-C. Lin, C. A. Tseng and S.-L. Lee, Surf. Coat. Technol., 2008, 202, 5425-5430.
74 A. L. Patterson, Phys. Rev., 1939, 56, 978-982.

75 E. H. Kisi and M. M. Elcombe, Acta Crystallogr., Sect. C: Cryst. Struct. Commun., 1989, 45, 1867-1870.

76 A. Yumak, G. Turgut, O. Kamoun, H. Ozisik, E. Deligoz, P. Petkova, R. Mimouni, K. Boubaker, M. Amlouk and S. Goumri-Said, Mater. Sci. Semicond. Process., 2015, 39, 103-111.

77 J.-C. Lin, K.-C. Peng, H.-L. Liao and S.-L. Lee, Thin Solid Films, 2008, 516, 5349-5354.

78 C. Zhu, J. Li, Y. Yang, X. Zhao, W. Zou, R. Tan and W. Song, Thin Solid Films, 2017, 634, 155-159.

79 R. Bel Hadj Tahar, J. Eur. Ceram. Soc., 2005, 25, 3301-3306.

80 T. Minami, H. Sato, K. Ohashi, T. Tomofuji and S. Takata, J. Cryst. Growth, 1992, 117, 370-374.

81 J. Tauc, R. Grigorovici and A. Vancu, Phys. Status Solidi, 1966, 15, 627-637.

82 S.-S. Lin, J.-L. Huang and P. Šajgalik, Surf. Coat. Technol., 2005, 191, 286-292.

83 A. Jain, P. Sagar and R. M. Mehra, Solid-State Electron., 2006, 50, 1420-1424.

84 P. L. Washington, H. C. Ong, J. Y. Dai and R. P. H. Chang, Appl. Phys. Lett., 1998, 72, 3261-3263.

85 A. Dolgonos, T. O. Mason and K. R. Poeppelmeier, J. Solid State Chem., 2016, 240, 43-48.

86 J. Sans, J. Sánchez-Royo, A. Segura, G. Tobias and E. Canadell, Phys. Rev. B: Condens. Matter Mater. Phys., 2009, 79, 1-9. 